\title{
Decomposition Processes in the Anomalous Supersaturated Solid Solution of Binary and Ternary Aluminium Alloys Alloyed with Sc and Zr
}

\author{
A.L. Berezina, T.O. Monastyrska*, O.A. Molebny, V.K. Nosenko \\ AND A.V. KOTKO \\ Institute for Metal Physics of the NAS of Ukraine, 36 Vernadsky Blvd., 03680 Kyiv, Ukraine
}

\begin{abstract}
Decomposition of supersaturated solid solution of aluminium alloys alloyed with Sc and Zr have been studied in the work. The binary hypereutectic Al-Sc alloys, hyperperitectic Al- $\mathrm{Zr}$ alloys and ternary $\mathrm{Al}-\mathrm{Sc}-\mathrm{Zr}$ alloys were chosen. Alloys were obtained by the melt-spinning. Melts were quenched from temperatures of $T=1000^{\circ} \mathrm{C}$ and $T=1400^{\circ} \mathrm{C}$. The crystallization of anomalously supersaturated solid solution $\left(T_{\text {quen. }}=1400^{\circ} \mathrm{C}\right)$ or the crystallization with the formation of "fan" structure $\left(T_{\text {quen. }}=100{ }^{\circ} \mathrm{C}\right)$ are possible. The decomposition of anomalously supersaturated solid solution is continuous, with the precipitation of nanosized spherical $\mathrm{Al}_{3} \mathrm{X}$ $(\mathrm{X}=\mathrm{Sc}, \mathrm{Zr})$ particles. The loss of thermal stability of $\mathrm{Al}-\mathrm{Sc}$ alloys is due to the loss of coherence of the strengthening $\mathrm{Al}_{3} \mathrm{Sc}$ phase. In $\mathrm{Al}-\mathrm{Zr}$ alloys the loss of strength is due to the formation of a stable tetragonal $\mathrm{DO}_{23}$-ordered $\mathrm{Al}_{3} \mathrm{Zr}$ phase. After co-alloying of $\mathrm{Al}$ by $\mathrm{Sc}$ and $\mathrm{Zr}$ a bimodal grained structure was observed for the hypereutectic ternary alloy $\left(T_{\text {quen. }}=1400^{\circ} \mathrm{C}\right)$. Nanosized grains of $50-60 \mathrm{~nm}$ were present on the boundaries of 1-2 $\mu \mathrm{m}$ large-sized grains. Transmission electron microscopy shows the formation of nanocomposite $\mathrm{Al}_{3} \mathrm{Zr} / \mathrm{Al}_{3} \mathrm{Sc}$ particles. The formation of $\mathrm{Al}_{3} \mathrm{Zr}$ shell changes the nature of the interfacial fit of the particle with the matrix and slows down the decomposition during the coalescence.
\end{abstract}

PACS: 64.70.dg, 81.07.Bc, 81.10.Fq

\section{Introduction}

The development of novel high-strength, heat-resistant aluminium alloys requires an increase in the volume fraction of particles of strengthening phase in aluminium matrix due to the formation of anomalous supersaturation with slightly soluble transition metals in Al. Conventional methods of quenching and aging the solid state are not effective in this case. The main task of the study is to examine the decomposition of anomalous supersaturated solutions by transition metals in $\mathrm{Al}$ obtained by quenching from the melt $[1,2]$. To solve this problem it is necessary:

- to study factors that determine the formation of anomalously supersaturated solid solutions in aluminium alloyed with slightly soluble refractory elements;

- to determine the kinetics and morphology of the decomposition of anomalously supersaturated solid solutions in rapidly quenched aluminium alloys;

- to study the thermal stability of structures obtained during decomposition and to assess the possibility of improving their thermal stability.

\footnotetext{
* corresponding author; e-mail: monast@imp.kiev.ua
}

\section{Experimental}

The materials investigated had to be provided with: high volume fraction and high precipitation density of the strengthening phase, as well as high thermal stability of the structure produced [3]. It was supposed that the high volume fraction would be provided during the decomposition of anomalously supersaturated solid solution obtained by the melt-spinning method; high precipitation density would be formed during continuous decomposition with the precipitation of particles which had a low activation energy for nucleation; thermal stability would be ensured due to a low surface energy and low misfit parameter of the matrix with the phase formed, as well as low solubility and low diffusion coefficient of the alloying element in the matrix [4]. The formation of the $L 1_{2}$-ordered phase, isomorphic to the matrix, during the decomposition meets the abovementioned requirements. Binary hypereutectic Al-Sc alloys, hyperperitectic Al-Zr alloys, and ternary $\mathrm{Al}-\mathrm{Sc}-\mathrm{Zr}$ alloys were chosen. The Sc and $\mathrm{Zr}$ are transition elements with unlimited solubility in each other. Alloys were cast with the cooling rate of $10^{2}-10^{3}{ }^{\circ} \mathrm{C} / \mathrm{s}$ on a copper plate, and with the cooling rate of $10^{5}-10^{6} \mathrm{C} / \mathrm{s}$, using melt-spinning method on the copper wheel with the rotation speed of $V_{\mathrm{L}}=30 \mathrm{~m} / \mathrm{s}$ and $V_{\mathrm{L}}=44 \mathrm{~m} / \mathrm{s}$. Two quenching temperatures of the melt were chosen: $1000^{\circ} \mathrm{C}$, which is higher than liquidus temperatures of the alloys studied, and $1400^{\circ} \mathrm{C}$, which is higher than the melting temperature of $\mathrm{Al}_{3} \mathrm{Sc}$ inter- 
metallic compound $\left(1320^{\circ} \mathrm{C}\right)$ but lower than the melting temperatures of $\mathrm{Al}_{3} \mathrm{Zr}\left(1560^{\circ} \mathrm{C}\right)$. The composition of aluminium alloy ribbons, the quenching temperature of melt $T$ and the copper wheel rotation speed $V_{\mathrm{L}}$ are summarized in Table I.

TABLE I

The composition of aluminium alloys and the processing parameters of ribbons.

\begin{tabular}{|c|c|c|c|c|c|}
\hline No & $\begin{array}{c}\mathrm{Al} \\
\text { [at.\%] }\end{array}$ & $\begin{array}{c}\mathrm{Sc} \\
{[\mathrm{at.} \%]}\end{array}$ & $\begin{array}{c}\mathrm{Zr} \\
\text { [at.\%] }\end{array}$ & $\begin{array}{c}\mathrm{T} \\
{\left[{ }^{\circ} \mathrm{C}\right]}\end{array}$ & $\begin{array}{c}V_{\mathrm{L}} \\
{[\mathrm{m} / \mathrm{s}]}\end{array}$ \\
\hline 1 & base & 0.67 & - & 1000 & 0 \\
\hline 2 & $"$ & 0.67 & - & 1400 & 0 \\
\hline 3 & $"$ & 0.67 & - & 1000 & 44 \\
\hline 4 & $"$ & 0.67 & - & 1400 & 44 \\
\hline 5 & $"$ & 1.2 & - & 1000 & 30 \\
\hline 6 & $"$ & 1.2 & - & 1000 & 44 \\
\hline 7 & $"$ & 1.32 & - & 1400 & 30 \\
\hline 8 & $"$ & 1.32 & - & 1400 & 44 \\
\hline 9 & $"$ & - & 0.33 & 1000 & 44 \\
\hline 10 & $"$ & - & 0.33 & 1400 & 44 \\
\hline 11 & $"$ & - & 1.2 & 1400 & 44 \\
\hline 12 & $"$ & 0.6 & 0.24 & 1000 & 30 \\
\hline 13 & $"$ & 0.6 & 0.24 & 1000 & 44 \\
\hline 14 & $"$ & 0.6 & 0.24 & 1400 & 30 \\
\hline 15 & $"$ & 0.6 & 0.24 & 1400 & 44 \\
\hline
\end{tabular}

The transmission electron microscopy JEM 2000FXII, conventional light microscopy, and microhardness measurement were used in the studies.

\section{Results and discussion}

3.1. The effect of quenching temperature of the melt on the structure of aluminum alloys

The TEM study of structural and phase states of aluminium alloys rapidly quenched with the cooling rate of $10^{5}-10^{6}{ }^{\circ} \mathrm{C} / \mathrm{s}$ showed that the quenching temperature change from 1400 to $1000{ }^{\circ} \mathrm{C}$ resulted in the crystallization mechanism change. Examination of $\mathrm{Al}-\mathrm{Sc}$ and $\mathrm{Al}-\mathrm{Zr}$ alloys showed that regardless of the alloying element, the melt quenching from $1400^{\circ} \mathrm{C}$ led to the formation of single-phase state, i.e. anomalous supersaturated solid solution (Fig. 1).

The highest concentration of the supersaturated solid solution was determined by the emergence of nanosized grains. In $\mathrm{Al}-\mathrm{Sc}$ alloys the increase in Sc concentration from 0.67 at.\% to 1.3 at.\% did not cause significant changes in the structure. In contrast, in $\mathrm{Al}-\mathrm{Zr}$ ribbons quenched from $1400{ }^{\circ} \mathrm{C}$ the increase in $\mathrm{Zr}$ concentration from 0.33 at.\% to 1.2 at.\% led to a large volume fraction of nanocrystalline structure. This state was characterized by a bimodal distribution of grain sizes. Nanosized grains of 50-60 nm were present on the boundaries of 1-2 $\mu \mathrm{m}$ large-sized grains. The presence of nanocrystalline grains accelerated the formation of metastable and stable phases during the decomposition of supersaturated solid solution. The structure had low thermal stability. The microhardness of the Al-1.2at.\%Zr alloy was $1300 \mathrm{MPa}$, which

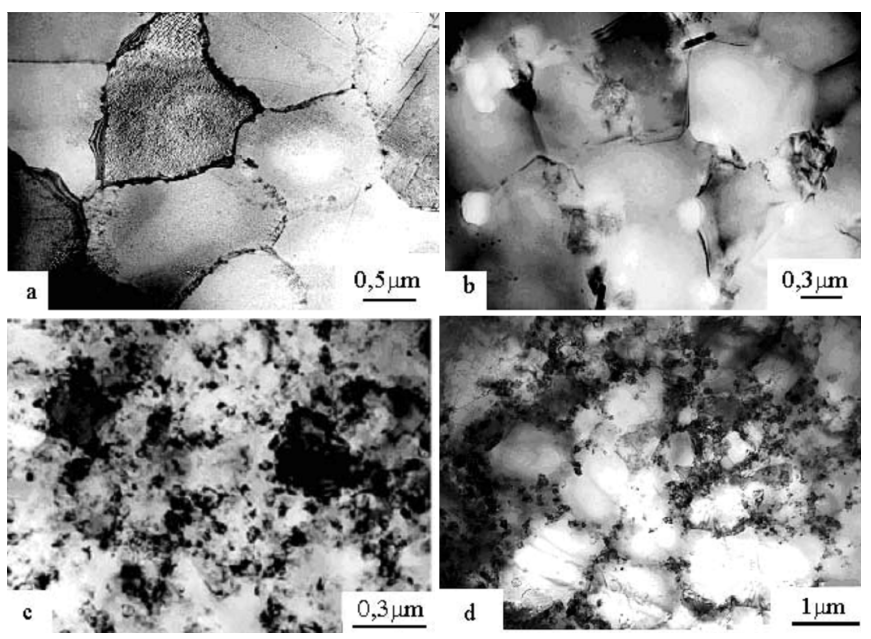

Fig. 1. The structure of the alloys quenched from $1400{ }^{\circ} \mathrm{C}$ : (a) Al-0.67at.\%Sc; (b) Al-0.33at.\%Zr; (c) $\mathrm{Al}-$ 1.2at.\%Zr; (d) Al-0.6at.\%Sc-0.24at.\%Zr.

is twice as high as the hardness of the $\mathrm{Al}-0.33 \mathrm{at} . \% \mathrm{Zr}$ alloy. The total supersaturation limit of ternary Al-Sc-Zr alloys was lower as compared to binary $\mathrm{Al}-\mathrm{Zr}$ and $\mathrm{Al}-\mathrm{Sc}$ alloys. The formation of nano-sized grains was observed for ternary Al-0.6\% Sc-0.24\% Zr alloy (Fig. 1d).

The melt quenching from $1000^{\circ} \mathrm{C}$ led to crystallization with the formation of "vortex" or "fan" structure (Fig. 2). The "vortex" structure covered several grains (Fig. 2a,c). "Fan" structures were inside grains (Fig. 2b,d). The thickness of the structure branches was about $10 \mathrm{~nm}$.

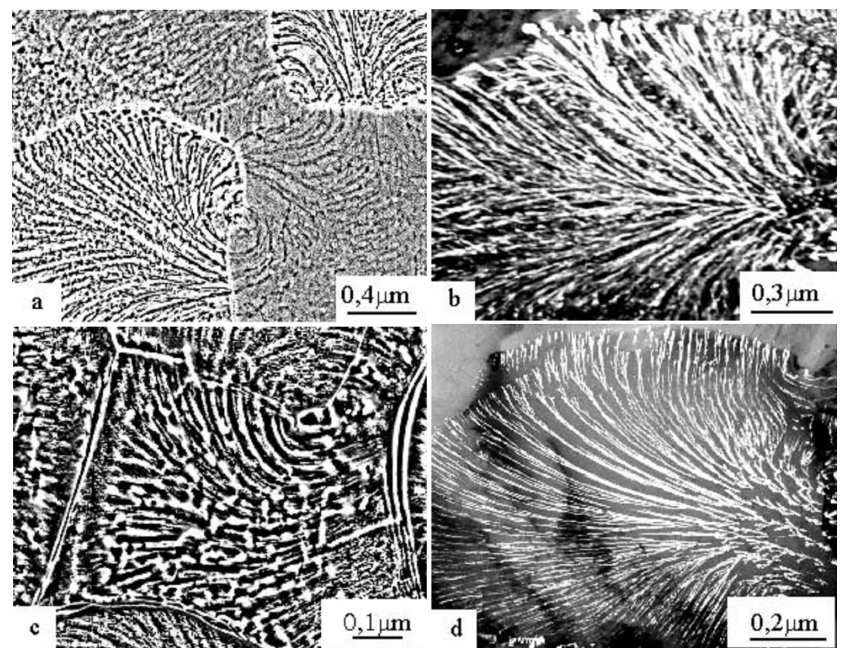

Fig. 2. The types of crystallized structures of alloys produced by melt-spinning from $1000{ }^{\circ} \mathrm{C}$ : "vortex" structure (a) Al-0.67at.\%Sc; (c) Al-0.33at.\%Zr; "fan" structure (b) Al-0.67at.\%Sc; (d) Al-033at.\%Zr.

The morphology of "fan" and "vortex" structures proves their crystallization origin. They grew directly from the melt and did not result from the transformation (cellular decomposition) in the solid state. 


\subsection{The effect of $Z r$}

The introduction of $\mathrm{Zr}$ in $\mathrm{Al}-\mathrm{Sc}$ alloy brought about certain peculiarities in the structure of rapidly quenched alloys as compared to binary ones. The bimodal distribution of grains with the nanocrystalline component was observed in ternary $\mathrm{Al}-\mathrm{Sc}-\mathrm{Zr}$ alloys after quenching from $1400^{\circ} \mathrm{C}$, in contrast to the binary $\mathrm{Al}-\mathrm{Sc}$ and $\mathrm{Al}-\mathrm{Zr}$ alloys with the same degree of supersaturation. Consequently, the cumulative effect of these elements exceeded the effect of each component. A decrease in the quenching temperature to $1000^{\circ} \mathrm{C}\left(V_{\mathrm{L}}=44 \mathrm{~m} / \mathrm{s}\right)$ led to the formation of single-phase state, i.e. anomalous supersaturated solid solution. The mixed structure was formed after the reduction of $V_{\mathrm{L}}$ to $30 \mathrm{~m} / \mathrm{s}$. The grains crystallized to form a solid solution and "fan"-structured grains present in the alloy. Faceted primary $\mathrm{Al}_{3} \mathrm{Zr}$ particles of the 400 $500 \mathrm{~nm}$ were also observed. Thus, the introduction of $\mathrm{Zr}$ in $\mathrm{Al}-\mathrm{Sc}$ alloys allowed us: to reduce the temperature of quenching for the formation of anomalously supersaturated solid solution, to reduce the total concentration of alloying elements for the formation of nanosized grain structure.

\subsection{Aging processes of rapidly quenched aluminium alloys}

The TEM study showed that regardless of the nature of the alloying elements ( $\mathrm{Sc}, \mathrm{Zr}$ ) in the initial stages of decomposition of the supersaturated solid solution the $\mathrm{Al}_{3} \mathrm{X}(\mathrm{X}=\mathrm{Sc}, \mathrm{Zr})$ strengthening $L 1_{2}$-ordered phase was formed. The $\mathrm{Al}_{3} \mathrm{Sc}$ stable phase particles induced static distortions in the matrix as a result of misfit of lattice parameters. The $\mathrm{Al}_{3} \mathrm{Zr}$ phase was metastable and did not induce static distortions in the matrix. It was established that the mechanism of decomposition and morphology of precipitated phase depended on the initial state of the alloy in accordance with the processing parameters. Ribbons crystallized with the formation of solid solutions (quenching from $1400^{\circ} \mathrm{C}$ ) continuously decomposed with the precipitation of chaotically distributed particles. The variation of the temperature and aging time allowed us to obtain a highly dispersed structure containing nanosized spherical $\mathrm{Al}_{3} \mathrm{X}(\mathrm{X}=\mathrm{Sc}, \mathrm{Zr})$ particles of $L 1_{2}$-ordered phase of about $2 \mathrm{~nm}$ size and the precipitation density $\approx 10^{18} \mathrm{~s} \mathrm{~m}^{-3}$.

Coherent $\mathrm{Al}_{3} \mathrm{Sc}$ particles were observed in the $\mathrm{Al}-\mathrm{Sc}$ alloy after aging at $450^{\circ} \mathrm{C}$ for $2 \mathrm{~h}$. The average size $d$, the precipitation density $N v$ and the volume fraction $f$ of particles are summarised in Table II.

TABLE II

Characteristics of $\mathrm{Al}_{3} \mathrm{X}$ particles after aging at $450{ }^{\circ} \mathrm{C}$ for 2 hours.

\begin{tabular}{c|c|c|c|c|c|c}
\hline \hline $\begin{array}{c}\text { Alloy } \\
\text { [at.\%] }\end{array}$ & $\begin{array}{c}T \\
{\left[{ }^{\circ} \mathrm{C}\right]}\end{array}$ & $\begin{array}{c}V_{\mathrm{L}} \\
{[\mathrm{m} / \mathrm{s}]}\end{array}$ & $\begin{array}{c}\text { Phase } \\
\text { type }\end{array}$ & $\begin{array}{c}d \\
{[\mathrm{~nm}]}\end{array}$ & $\begin{array}{c}N_{v} \\
{\left[\mathrm{~s} \mathrm{~m}^{-3}\right]}\end{array}$ & $\begin{array}{c}f \\
{[\%]}\end{array}$ \\
\hline $\mathrm{Al}-0.67 \mathrm{Sc}$ & 1400 & 44 & $L 1_{2}$ & 22 & $4.5 \times 10^{15}$ & 2.5 \\
$\mathrm{Al}-1.32 \mathrm{Sc}$ & 1400 & 44 & $L 1_{2}$ & 15 & $1.8 \times 10^{16}$ & 3.2 \\
$\mathrm{Al}-1.32 \mathrm{Sc}$ & 1400 & 30 & $L 1_{2}$ & 19 & $1.1 \times 10^{16}$ & 4.6 \\
$\mathrm{Al}-0.33 \mathrm{Zr}$ & 1400 & 30 & $L 1_{2} / D O_{23}$ & 9 & $2.3 \times 10^{16}$ & 1.2
\end{tabular}

The tendency of the particles being situated on dislocations was observed. When the particle sizes were about $30 \mathrm{~nm}$, they lost coherency due to the formation of misfit dislocations at the interphase boundary.

Alloys which crystallized with the formation of "fan" structure (quenching from $1000{ }^{\circ} \mathrm{C}$ ) decomposed through thickening of the structure branches and formation of spherical precipitates of $\mathrm{Al}_{3} \mathrm{X}(\mathrm{X}=\mathrm{Sc}, \mathrm{Zr}) L 1_{2}$-ordered phase between the branches. Destruction of the "fans" occured during the aging process. Evolution of structure led to the formation of chaotically distributed particles of $\mathrm{Al}_{3} \mathrm{X}(\mathrm{X}=\mathrm{Sc}, \mathrm{Zr}) L 1_{2}$-ordered phase with the precipitation density $\approx 10^{15} \mathrm{~s} \mathrm{~m}^{-3}$ (Al-Sc alloys) and $\approx 10^{16} \mathrm{~s} \mathrm{~m}^{-3}$ (Al-Zr alloy). Further evolution of these structures was similar to that of alloys, crystallized with the formation of solid solutions.

\subsection{Thermal stability of structures formed by rapid quenching}

The morphology of the decomposition after long-term aging at high temperatures was studied to determine the thermal stability of the structure obtained (Fig. 3). Comparison of structural changes during isothermal ag-

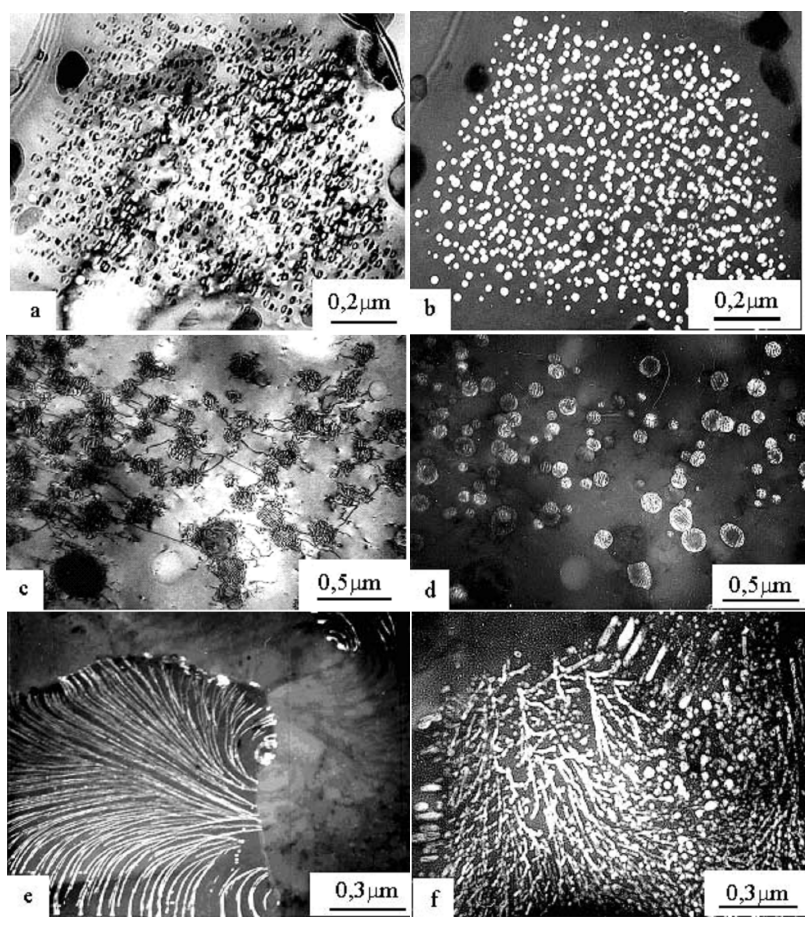

Fig. 3. Decomposition processes in the $\mathrm{Al}-1.32$ at. \% Sc ribbons crystallized: (1) with the formation of solid solutions, quenching from $1400^{\circ} \mathrm{C}$ at $V_{\mathrm{L}}=44 \mathrm{~m} / \mathrm{s}:(\mathrm{a}),(\mathrm{b})$ aging at $450{ }^{\circ} \mathrm{C}$ for 2 hours, the particle size $d \approx 15 \mathrm{~nm}$ $N_{v} \approx 10^{16} \mathrm{sm}^{-3} ;(\mathrm{c}),(\mathrm{d})$ aging at $450^{\circ} \mathrm{C}$ for $20 \mathrm{~h}$, the particle size $d \approx 87.4 \pm 2.6 \mathrm{~nm}, N_{v} \approx 10^{14} \mathrm{sm}^{-3} ;(2)$ with the formation of "fan" structure, quenching from $1000{ }^{\circ} \mathrm{C}$ at $V_{\mathrm{L}}=44 \mathrm{~m} / \mathrm{s}$ : (e) after quenching, the thickness of the "fan" branches $\approx 5 \mathrm{~nm}$; (f) aging at $450{ }^{\circ} \mathrm{C}$ for 2 hours, the particle size $d \approx 19.2 \pm 2.4 \mathrm{~nm}$. (a), (c), (e) bright-field image, (b), (d), (f) dark-field image in reflex (100) of the $\mathrm{Al}_{3} \mathrm{Sc}$-phase. 
ing and changes in microhardness showed that the increase of hardness was due to the formation of $\mathrm{Al}_{3} \mathrm{X}$ (X $=\mathrm{Sc}, \mathrm{Zr}) L 1_{2}$-ordered phase. The most high-strength state was achieved in the alloys, crystallized with the formation of solid solutions.

The decrease in microhardness below the initial value was found after aging of the Al-Sc alloys at $T>300^{\circ} \mathrm{C}$, and the $\mathrm{Al}-\mathrm{Zr}$ alloys at $T>350^{\circ} \mathrm{C}$. Alloys, which crystallize with the formation of "fan" structure, were thermally the most stable of the binary alloys.

It was found that the loss of strength of Al-Sc alloys was due to the loss of coherence of the strengthening $\mathrm{Al}_{3} \mathrm{Sc}$ phase particles (Fig. 3b,d). In Al-Zr alloys the loss of strength was due to the formation of a stable tetragonal $\mathrm{DO}_{23}$-ordered $\mathrm{Al}_{3} \mathrm{Zr}$ phase.

The $\mathrm{Al}_{3} \mathrm{Zr}$ metastable phase particles were replaced by composite $L 1_{2} / D O_{23}$ particles during aging at $450^{\circ} \mathrm{C}$ in $\mathrm{Al}-\mathrm{Zr}$ alloys (Fig. 4). The plate-like stable phase was formed inside the metastable phase particle (the size $\approx 10 \mathrm{~nm}$ ) along $\langle 100\rangle$. Further aging resulted in complete dissolution of the metastable phase and the formation of a rod-like stable phase with the length of about $80 \mathrm{~nm}$ after $70 \mathrm{~h}$ of aging (Fig. 4).

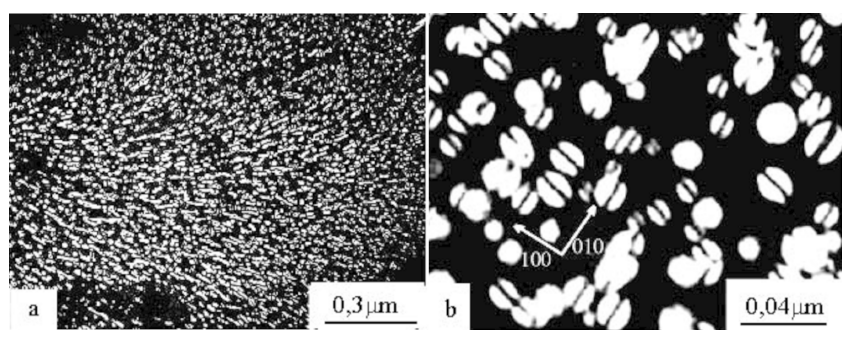

Fig. 4. The structure of the Al-0.89at.\% $\mathrm{Zr}$ alloy quenched from $1000{ }^{\circ} \mathrm{C}$ at $V_{\mathrm{L}}=44 \mathrm{~m} / \mathrm{s}$ and aged at $450{ }^{\circ} \mathrm{C}$ for $60 \mathrm{~h}$.

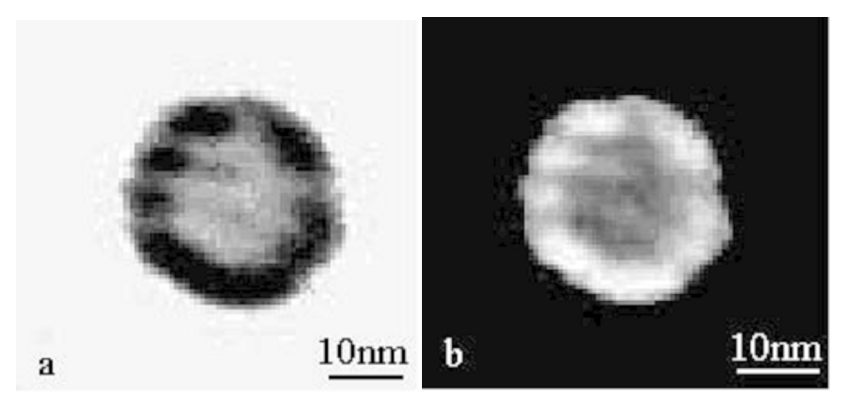

Fig. 5. The morphology of $\mathrm{Al}_{3} \mathrm{Zr} / \mathrm{Al}_{3} \mathrm{Sc}$ phase precipitate: (a) bright-field image, (b) dark-field image in superstructural reflex (100).

The continuous decomposition of the anomalous supersaturated solid solution of $\mathrm{Al}-0.6 \% \mathrm{Sc}-0.24 \% \mathrm{Zr}$ ternary alloy obtained by rapid quenching from $1000{ }^{\circ} \mathrm{C}$ at $V_{\mathrm{L}}=$ $44 \mathrm{~m} / \mathrm{s}$ are most interesting. Two alloying elements of the alloy have a considerable difference in diffusion mobility $D_{\mathrm{Sc}} / D_{\mathrm{Zr}} \approx 10^{3}$ and the difference in the mis- fit parameters of the matrix and the $\mathrm{Al}_{3} \mathrm{X}$ intermetallic $\delta_{\mathrm{Al3Sc}} / \delta_{\mathrm{Al3Zr}} \approx 2$. Therefore one could expect that the nucleation processes of decomposition would be determined by the diffusion mobility of Sc, and the processes of growth and coalescence - by Zr diffusion. This facilitates the formation of nanocomposite $\mathrm{Al}_{3} \mathrm{Zr} / \mathrm{Al}_{3} \mathrm{Sc}$ particles with $\mathrm{Al}_{3} \mathrm{Sc}$ core and $\mathrm{Al}_{3} \mathrm{Zr}$ shell. The morphology of such particles is shown in Fig. 5 .

The formation of $\mathrm{Al}_{3} \mathrm{Zr}$ shell changed the nature of the interfacial fit of the particle and the matrix and slowed down the decomposition during the coalescence stage. Reduction in size of particles formed after long-term aging due to the 0.24 at.\% $\mathrm{Zr}$ addition in $\mathrm{Al}-0.6$ at.\% $\mathrm{Sc}$ alloy is shown in Fig. 6.

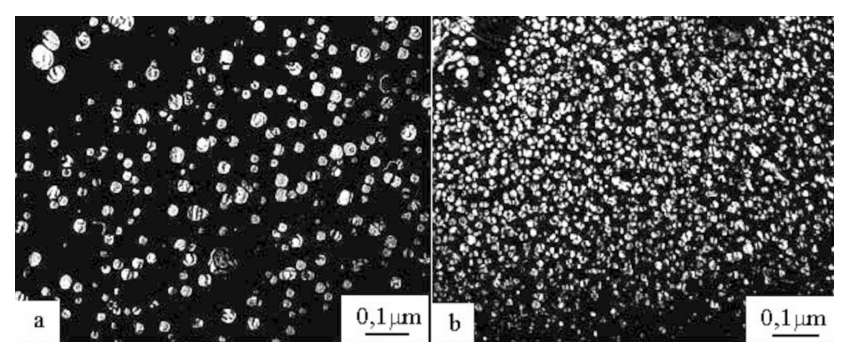

Fig. 6. The dark-field image in superstructural reflex (110) of the $\mathrm{Al}_{3} \mathrm{X}$ phase of the alloys: (a) $\mathrm{Al}-0.6 \mathrm{at} . \% \mathrm{Sc}$, quenching from $1400{ }^{\circ} \mathrm{C}$ at $V_{\mathrm{L}}=44 \mathrm{~m} / \mathrm{s}$, aging at $450{ }^{\circ} \mathrm{C}$ for $2 \mathrm{~h}$; (b) Al-0.6at.\%Sc-0.24at.\%Zr, quenching from $1000{ }^{\circ} \mathrm{C}$ at $V_{\mathrm{L}}=44 \mathrm{~m} / \mathrm{s}$, aging at $450{ }^{\circ} \mathrm{C}$ for $40 \mathrm{~h}$.

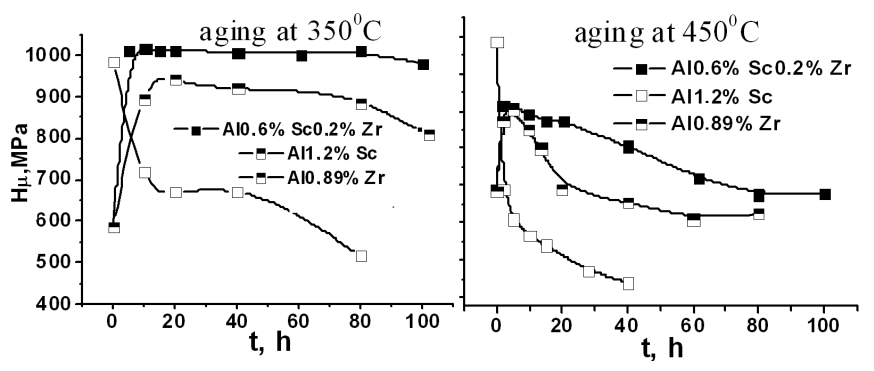

Fig. 7. Microhardness change after isothermal aging.

The microhardness change during isothermal aging at the temperatures 350 and $450{ }^{\circ} \mathrm{C}$ for alloys rapidly quenched from $1000^{\circ} \mathrm{C}$ is shown in Fig. 7. The data presented imply that ternary $\mathrm{Al}-\mathrm{Sc}-\mathrm{Zr}$ alloys have significantly higher thermal stability during aging at the temperatures 350 and $450^{\circ} \mathrm{C}$ as compared to binary Al-Sc and $\mathrm{Al}-\mathrm{Zr}$ alloys.

\section{Conclusions}

1. The Al-Sc and Al-Zr alloys are solidified with the formation of anomalously supersaturated solid solution at quenching temperature of $1400^{\circ} \mathrm{C}$. The "fan" structures are solidified at quenching temperature of $1000^{\circ} \mathrm{C}$. 
2. The introduction of $\mathrm{Zr}$ in Al-Sc alloys allows one to reduce the temperature of melt quenching from $1400^{\circ} \mathrm{C}$ to $1000^{\circ} \mathrm{C}$ for the formation of anomalously supersaturated solid solution.

3. The loss of thermal stability of Al-Sc alloys is due to the loss of coherence of the strengthening $\mathrm{Al}_{3} \mathrm{Sc}$ phase particles. In $\mathrm{Al}-\mathrm{Zr}$ alloys the loss of thermal stability is due to the formation of a stable tetragonal $\mathrm{DO}_{23}$-ordered $\mathrm{Al}_{3} \mathrm{Zr}$ phase.

4. The nanocomposite $\mathrm{Al}_{3} \mathrm{Zr} / \mathrm{Al}_{3} \mathrm{Sc}$ particles with $\mathrm{Al}_{3} \mathrm{Sc}$ core and $\mathrm{Al}_{3} \mathrm{Zr}$ shell form in ternary $\mathrm{Al}-\mathrm{Sc}-\mathrm{Zr}$ alloys during high temperature aging. The formation of $\mathrm{Al}_{3} \mathrm{Zr}$ shell changes the nature of the interfacial fit of the particle and the matrix, slows down the decomposition during the coales- cence stage, which improves the thermal stability of alloys.

\section{References}

[1] A.L. Berezina, U. Schmidt, T.A. Monastyrska, Mater. Sci. Forum 396-402, 763 (2002).

[2] A.L. Berezina, K.V. Chuistov, T.A. Monastyrska, Metallofiz. Noveishie Tekhnol. 25, 1001 (2003).

[3] A.L. Berezina, E.A. Segida, V.K. Nosenko, Electron Microsc. Strength Mater. 14, 57 (2007).

[4] A.L. Berezina, E.A. Segida, N.N. Budarina, A.V. Kotko, G.S. Mogilnyi, Metallofiz. Noveishie Tekhnol. 30, 647 (2008). 